\title{
Reuben Hersh 1927-2020 Critic and Philosopher of Mathematics
}

\author{
Ulf Persson (Chalmers University of Technology, Göteborg, Sweden)
}

Reuben Hersh died just after New Year this year, having just turned ninety-two a few weeks before. I first heard of him in the early $80 \mathrm{~s}$ in connection with the book The Mathematical Experience, written along with Philip Davis. The book had just made a splash, as far as a mathematically oriented book can make a splash outside of the mathematical community. It had been reviewed by Martin Gardner in the New York Review of Books, which was considered an honour. And it also won a National Book Award. It is indeed a wonderful book, written by regular mathematicians and not philosophers or journalists. I recall a conversation at the IAS at the time when Armand Borel praised it, partly for that reason, and Borel would not praise without very good reason. Although I loved the book, I cannot, almost forty years later, really recall its contents. This is not atypical when you read something and thoroughly digest it. You may not be consciously aware of it, but it has worked its influence deeply. Flipping through the pages in connection with writing this text, I realised that many things I now know I had picked up there, and many things I thought I had made up myself, I could likewise find in its pages.

The book was a joint project with Philip Davis, a numerical analyst at Brown. As a reader you may be puzzled that it is written in the first person. Who is this person? Hersh or Davis? Sometimes Hersh and sometimes Davis, in fact. The explanation being that it is actually two books which were merged. Davis was working on a book on mathematics for the layperson, a genre in which he had some previous experience ${ }^{1}$, while Hersh was writing on the philosophy of mathematics, so the overture of the book refers to the genesis of that project. ${ }^{2}$

Hersh told me that he did indeed give a course on the philosophy of mathematics in the time-honoured tradition of wanting to learn something new. As he did so, he realised that he did not have a philosophical point of view himself. Was he a Platonist, a Formalist or maybe even a

1 In fact, in my early teens I read and enjoyed a Swedish translation of The Lore of Large Numbers, which I only recently realised was written by him.

2 In Experiencing Mathematics Hersh writes: "I was fortunate in establishing a partnership with Philip J. Davis. He wanted to write math for the intelligent non-mathematician, while I wanted to write philosophy of math, so we agreed to work in parallel, for mutual support. Unfortunately, I was overwhelmed by deep personal problems. I wrote what I could, and then collapsed. Amazingly, Phil and Hadassah were able to sew together Phil's chapters and mine, into some kind of a coherent book. More amazingly, the book became a best seller, so far as math books go, and won a National Book Award."

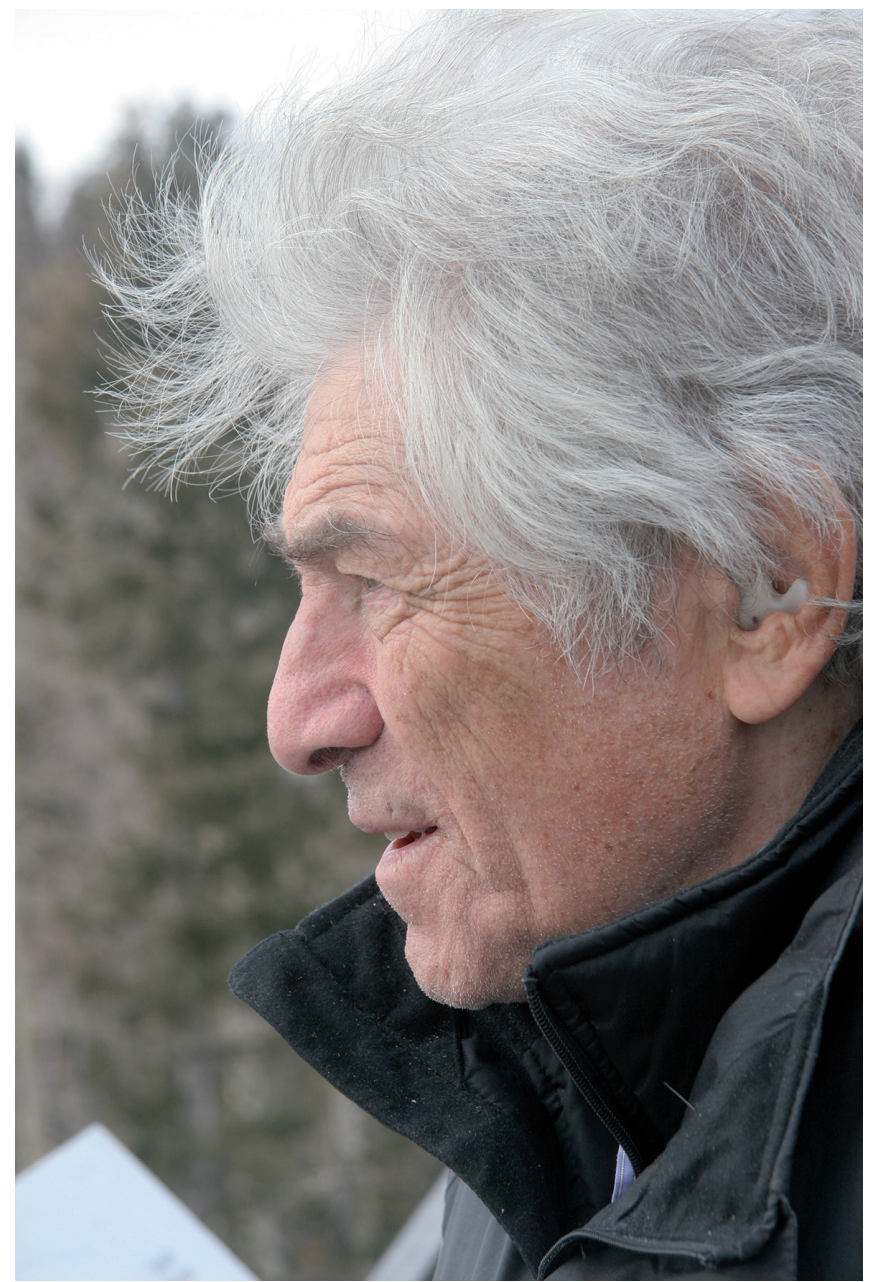

Reuben Hersh (February 2011).

Intuitionist? He wanted to find out, and what better way to do so than to write a book? The two became a team and went on to write one more joint book (Descartes' Dream). Hersh would then eventually strike out on his own and write books with titles such as What is mathematics, Really? and, jointly with his partner Vera JohnSteiner, Loving and Hating Mathematics. Four books which form a loosely connected series. But this was of course not his last writing. He would go on writing a lot of articles as well as writing a biography on his mentor and advisor Peter Lax. Although it was the book The Mathematical Experience which brought their names to my and many other people's attention.

The book has in many ways the character of a scrap book, as it consists of short sections (grouped into lengthier chapters) on a variety of topics, sometimes loosely tied together, sometimes tightly so. They are also 


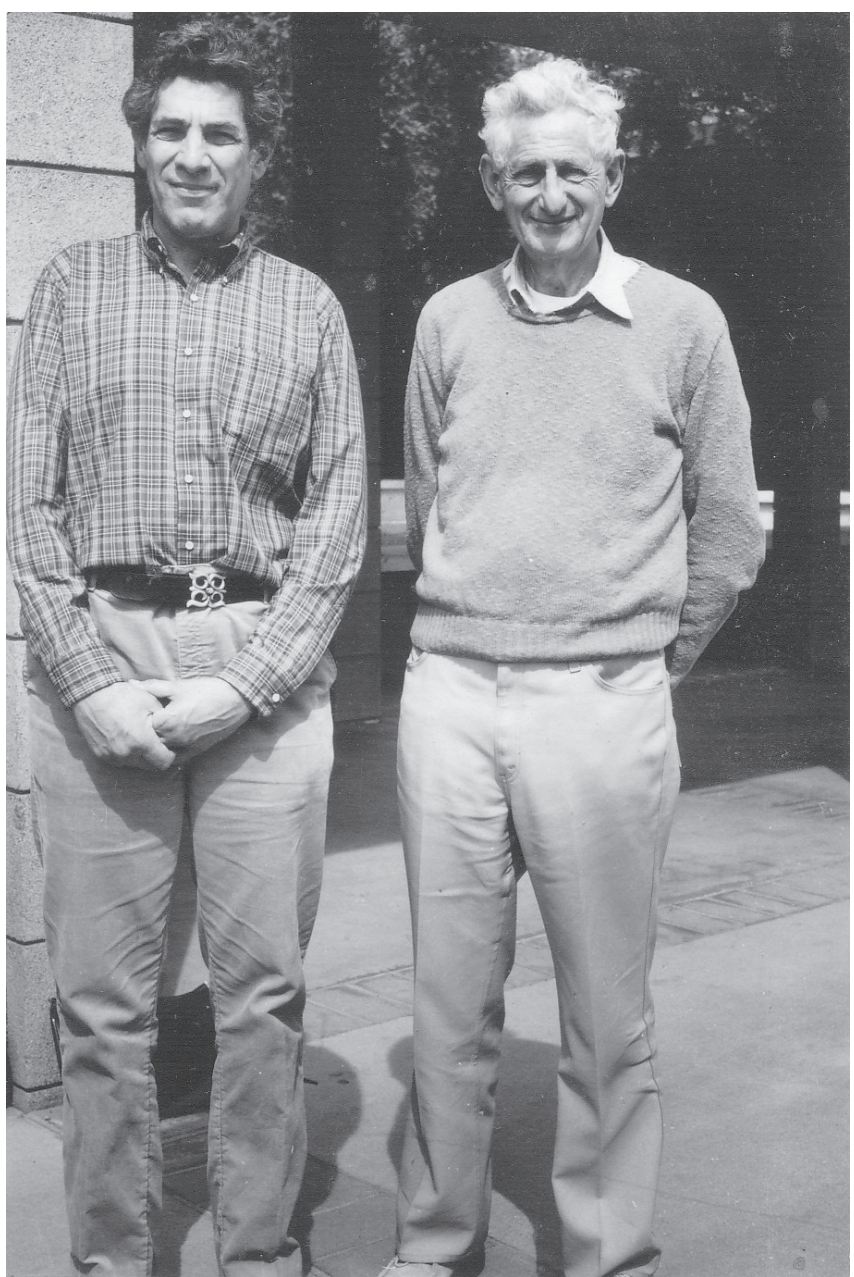

Reuben Hersh and Philip Davis.

written in different styles, some very light-hearted in their forms of imaginary interviews, others more regular discourse. This makes the book easy to read, in fact a real page turner, as it does not put undue demands on your attention span, but instead invites you to happily race along, wondering what is going to happen next. It does contain a fair amount of mathematics, but although addressing a wider, mostly non-mathematical audience, it does not fall in the didactic trap which makes so much of mathematics get dumbed down, ostensibly for the benefit of the ordinary reader, and so painful for the professional mathematician to read. The secret is that most of the book, apart from playful interludes, is written in the manner of essays. And what is an essay? It is an attempt to find out what you think ${ }^{3}$ and (optionally) letting others eavesdrop on you.

So when the authors expound on some mathematics, they do so in order to look at it critically and philosophically with fresh eyes, thus putting themselves at the same level as the reader, viewing the material both with the

\footnotetext{
3 I picked this up from the American diplomat George Kennan, who reveals in his autobiography that the real reason he wrote all those dispatches was not for the ostensible recipient - the State Department, which he did not expect to read them, but for himself, in order to find out what he really thought.
}

innocence of the ignorant and the retroactive wisdom of the expert. This does not mean that the book is perfect, I personally find that the short section on non-Euclidean geometry leaves much room for improvement, even without having to be extended in bulk. But the real interest of the book, as well as its greatest impact, has to do with Hersh's take on traditional mathematical philosophy. In the past there really was little distinction between a scientist and a philosopher, you tended to be a little bit of both in as far as you were at least a little bit of either. In the 19th century it was not uncommon for a physicist to become a philosopher in old age, examples are Mach and to some extent Boltzmann. Einstein's approach to relativity was as much that of a philosopher as a mathematician. And at the turn of the century, mathematicians such as Hilbert, Weyl and Brouwer were also philosophers. On the other hand, philosophers such as Russell and Wittgenstein were not mathematicians, although Russell made valiant efforts. Nowadays it is rare to find a mathematician with not only a philosophical interest but also an active engagement with it. With this book, Hersh proved himself to be one of the rare birds. ${ }^{4}$

In the book, Hersh looks at Platonism, formalism and intuitionism, and rejects them all as being far too restrictive. Platonism he finds downright embarrassing with its references to an abstract world beyond space and time, and thus not much above ancient superstition; but he agrees that most working mathematicians tend to be naive Platonists, although they may not admit it openly. Formalism, introduced by Hilbert ${ }^{5}$, Hersh dismisses as a caricature of mathematical practice, turning it into a meaningless game. Intuitionism, on the other hand, he is very sympathetic to, yet finds it in many ways too extreme in its radical rejection of the exclusion of the middle third. While most mathematicians are Platonist at heart, although when pressed may make references to the formalist foundation of mathematics, few mathematicians are in fact practicing intuitionists, a movement Hersh sees in terms of being an heretic sect, although he does appreciate many of its points and thus they act like a salt in the mathematical community. He concludes that mathematics is too rich and mysterious to be straitjacketed into one of those three slots. Each category admittedly provides a view of mathematics, but a very limited one. He compares it to the various views of a cube projected onto the plane. The projections do look like different pictures; only when you can fathom the full 3-dimensional cube do they make sense taken together. The same is true with mathematics. Incidentally a very Platonic metaphor. Along with the rejection of the three 'isms' of mathematical philosophy, he takes exception

4 Another rare bird was Gian-Carlo Rota, who was in fact a card-carrying phenomenologist and an enthusiastic follower of Edmund Husserl. Rota incidentally provides the book with a foreword.

5 But Hilbert was never a formalist at heart, formalism he espoused only for very specific technical purposes; namely the dream of mathematically proving the consistency of mathematics, and thus keeping the paradise safe. 
to the undue emphasis on foundations in contemporary philosophy of mathematics. These questions do not really interest him, in fact he finds them sterile dead-ends. Mathematics provides such a wealth of interesting food for philosophical thought, so there is no need to fixate yourself on scholastic speculations. When it comes to his own philosophy of mathematics, he takes as his point of departure two apparently irreconcilable facts. The first fact is that mathematics is done and created by humans, the second fact is that, unlike art, which is also done and created by humans, it is nevertheless a science. As every working mathematician experiences, the concepts he or she encounters and maybe even creates are not arbitrary, but are forced on you. The mathematical reality kicks back at you and becomes very palpable in spite of the abstractness of its mental concepts ${ }^{6}$. There is no subjectivity when it comes to mathematics, unlike in the arts, and there is also a remarkable consensus when it comes to mathematics, a consensus you would never find in any other human endeavour. The formalists would attribute this to the ironclad rules of logic, but it is a well-kept secret among mathematicians that the consensus and unity of mathematics goes deeper than mere logical compulsion. Deductive reasoning does play an important role in mathematics, similar to that of election in democracies, but it is far from the full story; I am fond of comparing the logical foundation of mathematics with presenting a picture pixel by pixel.

How can we reconcile these very different aspects of mathematics? We simply have to, because mathematics is there. Out there? We may provocatively ask him. No, Hersh replies, not out there but within us. Not within individuals as much as within mankind itself, there is no reason to look for it anywhere else. To me this seems very close in spirit to Carl Jung's notion of the collective unconsciousness. But never mind, the Jungian vision may strike the reader as mere mysticism, however, I think it nevertheless has great potential. Yet to explain mathematics by it presents an even greater challenge than that of explaining art, which was the original intention of Jung. Hersh does not refer to Jung (although he uses the term 'collective consciousness' a few times), instead he refers to Karl Popper and his World3 of mental constructs. Maybe that constitutes a 'collective consciousness' born out of a mysterious 'collective unconsciousness'? Hersh, by the way, is no stranger to ascribing a measure of mystery to many mathematical facts. The reference to Popper is significant, as Popper did not count mathematics as a science, as its results were based on deduction and thus not straddled with the problems of induction. In this respect, I think Popper was mistaken, and one of his students Imre Lakatos - actually made a serious start on viewing mathematics from a Popperian point of view (actually a subject for one of the sections in the book). But the

\footnotetext{
${ }^{6}$ I would personally argue that, just as reality becomes palpable due to the consistency of all our senses in perceiving it, mathematics thrives on the consistency of so many different approaches, which makes up for a remarkable degree of interrelatedness.
}

legacy of Hersh does not consist of viewing mathematics as a science (let alone the horrible thought of merely being a language for the same), but putting it firmly in the humanistic camp. As a philosopher, he was not accepted by the community of professional philosophers, while he on the other hand did not think that they really understood mathematics.

So how could one pursue an interesting and fruitful philosophical study of mathematics? Hersh does not formulate any definite answers, but the book and his other writings make suggestions. Maybe it would be more instructive to view Hersh not so much as a philosopher of mathemetics, but as a cultural critic of it. Personally, I think that there is a need for mathematical critics who do the critical work that is done in literature and the arts, especially in view of the bureaucratic way mathematical achievement tends to be judged academically in matters of promotion. But how to start? I am tempted to refer to the British philosopher and historian R.G. Collingwood and his view on the relationship between philosophy and history. Collingwood took exception to the analytic philosophy practiced in his days, and instead stressed the moral responsibility of philosophy and thus how its study related to man. Thus history was his main philosophical concern. Not history of the trivial 'cutting and pasting' variety, but history which puts human thought at its centre, and thus makes intelligible its acts as being the outcome of human intentions. It is exactly the presence of human intentions which makes history as we know it differ profoundly from natural history, in which mankind has no role. This view by Collingwood has been criticised, among others by Popper, as being too subjective, but there is a very strong objective component to human thought (as exemplified by the notion of intention), which is the one that interests Collingwood and to which Hersh refers, at least implicitly, as manifested by mathematics. Pursuing a history of mathematics putting the mental history at its core would be, I believe, one fruitful avenue to exploring Hersh's humanistic view of mathematics. As Collingwood puts it, you cannot move the past into the present, not even fragments of it (pace Marcel Proust), but you can reconstruct it in the context of the present, just as we reconstruct mathematical ideas when we ponder a proof. Thus a history of mathematics should not be so much a documentation of who did what and when, but an exploration of the evolution of ideas and how they interact and their dependence on actual time.

In 2007 I picked up Hersh's What is mathematics, really?, the title being an obvious take on the book by Courant and Robbins What is mathematics? I contacted 
the author and we soon established a delightful e-mail exchange which would continue up to his death. I met him only once in person, when I was dispatched to his home in New Mexico in early 2011. ${ }^{7}$ I stayed over at his and his partner Vera's adobe house for a few days, during which time we had a continuous conversation. I wrote some of it down in the form of an interview with his active assistance, the link to which will be listed below. We touched upon a great variety of topics, as his interests ranged widely, and he was never short on thoughts or words. He made me feel very welcome by claiming that it was so nice to be able to talk and discuss matters that mattered to him deeply and which would only bore those around him. He was already an old man when we met, in fact well into his eighties, and his appearance with a full head of white hair made me think of an old American Indian chief (later on, I learned from pictures, he grew a long beard and my associations turned to Walt Whitman). He was fit enough to beat me at ping-pong and, apart from some hearing loss, he showed few if any of the signs of aging, in particular none of the befuddlement which often degrade the final years of the elderly. His mind was lucid then and would continue to be so almost until the end, I have been told. At the time of my visit, he was promoting his book with Vera on loving and hating mathematics, which focused on the psychology of mathematicians or more precisely how encountering mathematics affects you. When I made some ironic remarks about his concerns for marketing it, he told me that you look out for your books as if they were your children and I should just wait and see until I was publishing my first book. Unfortunately, the book did not receive the attention that the authors had hoped for, and some of the reviews were even hostile. I wrote one review and sent it to Hersh, who responded very warmly; as I suspect it was not entirely due to politeness and thus constituting some sort of confirmation that it at least gave a fair description of the book, I include a link below.

We both left for the airport in a shared taxi before dawn. I had to fly back to the East Coast, he had to meet with his advisor Peter Lax in connection with his work on the above-mentioned biography. The early hour of the day in no way impaired his volubility, on the contrary, being on the eve of the conclusion of our get-together it was instead enhanced. We never met again, but our e-mail exchanges continued, refreshed by our personal meeting.

We did not always agree on our views of mathematics, anything else would of course have been surprising, not to say disturbing. The greatest source of dissension was our view on Platonism in mathematics. He was puzzled by my stand, naturally, as his conception of Platonism was a bit too crude and literal in my opinion; on the other hand I never managed to present a version of Platonism that he could embrace. This could be construed as an unbridgeable division as supposedly between deists and atheists; but in fact it had very little impact on our mutual sympathy and respect and was to be seen merely as a matter of rhetoric rather than of any real substance. What mattered was what we shared.

No one lives forever, not even the long-living, and it is with sadness I note that I have lost a most stimulating discussion partner. His legacy, as noted above, is that he was a very articulate proponent for the human side of mathematics and that the philosophy of mathematics was too rich and important to be left to the professionals.

\section{Remarks and links}

A memorial site can be found at https//sites.google.com/view/in-memory-of-reuben-hersh.

The interview is accessible at the memorial site or directly from https:// sites.google.com/view/in-memory-of-reuben-hersh/interview-with-ulfpersson-2011

It contains some biographical material.

The review of Loving and Hating Mathematics can be found on http:// www.math.chalmers.se/ ulfp/remat.html

In 2008 I invited a few mathematicians to expound on mathematical Platonism in the Newsletter. Some wrote in favour, others critically, and among them were Hersh: https://www.ems-ph.org/journals/newsletter/ pdf/2008-06-68.pdf (page 17)

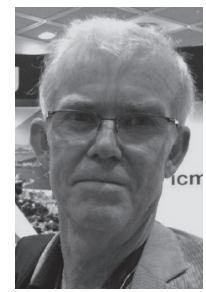

Ulf Persson is a member of the Editorial Board of the Newsletter. A detailed biography can be found in previous Newsletter issues, e.g. NL 107, March 2018.

\footnotetext{
7 Sent by the Swedish institution NCM (National Center for Mathematics, an institution devoted to the teaching of mathematics) by its director Bengt Johansson.
} 